\title{
Pedagogía intercultural: ¡un eufemismo para tranquilizar conciencias o una alternativa para la transformación?
}

\author{
Juan Rafael Gómez Torres ${ }^{1}$ \\ Centro de Investigación y Docencia en Educación (CIDE) de la Universidad Nacional \\ Heredia, Costa Rica
}

Recibido 13 de agosto de 2009• Aceptado 02 de diciembre de 2009

\begin{abstract}
Resumen. Este escrito intenta revisar algunos aspectos de la pedagogía costarricense desde el ámbito de la epistemología, la ética y la política como dimensiones fundamentales de la educación. Después se examinan sus prácticas interculturales, y se determina si lo que llamamos en el CIDE (UNA) pedagogía intercultural es un eufemismo más que nos viene de afuera y desde arriba, si lo acogemos sin mayor análisis, con el fin de no desestabilizar nuestro confortable estar en el mundo o es, en realidad, una alternativa de transformación de la sociedad costarricense.
\end{abstract}

Palabras clave. Pedagogía, pedagogía crítica, pedagogía intercultural, pedagogía de la diferencia, discriminación, eufemismo y exclusión social.

Abstract. The present article it entails the revision of some aspects of the Costa Rican pedagogy, especially in the epistemology area, ethics and the policies as fundamental dimensions of education. From there, it also proposes the revision of its intercultural practices in order to determine whether what it is called in the CIDE (UNA) Intercultural Pedagogy it is just another euphemism than comes from outside and above. If we receive it without major analysis in order not to disturb our comfortable being in the world, reality, or as an alternative of transformation of the Costa Rican society.

Key words. Pedagogy, critical pedagogy, intercultural pedagogy, pedagogy of the difference, discrimination, euphemism and social exclusion.

\footnotetext{
${ }^{1}$ Máster en Estudios Latinoamericanos con énfasis en Cultura y Desarrollo, Licenciado en Administración Educativa, Bachiller en Filosofía, en Enseñanza de la Filosofía, en Teología, en Enseñanza de la Religión y en Administración Educativa. Profesor e investigador en la División de Educología del Centro de Investigación y Docencia en Educación (CIDE) de la Universidad Nacional (UNA), Costa Rica.

Correo electrónico:ggomezz1@gmail.com
}

La Revista Electrónic@ Educare está indizada en el Catálogo LATINDEX.

Artículo protegido por la licencia Creative Commons. 
"Si en nuestra época es posible que un sistema de opresión permita a una minoría explotar a la mayoría, la razón reside en una cierta complicidad de la población, complicidad que se extiende a todos los dominios."

Bertolt Brech

Este ensayo es fruto de las reflexiones y acciones llevadas a cargo en el curso Pedagogía intercultural de la Licenciatura de Pedagogía con énfasis en didáctica, perteneciente a la División de Educología (CIDE, UNA). Esta licenciatura es de modalidad semipresencial ${ }^{2}$ y bajo esas condiciones ofrece la oportunidad de participación activa y propositiva, mediante la discusión y las problematizaciones de realidades, retos y perspectivas de la educación costarricense; desde allí, deseo manifestar algunas inquietudes generadas en el contexto de esos debates:

Considero que la pedagogía, sea cual sea el enfoque, debe revisar su quehacer epistemológico, esto es, debe reflexionar desde dónde hace o fundamenta su reflexión, explicando la necesidad de ubicar qué paradigma ${ }^{3}$ la fundamenta. En ese contexto, los y las docentes, a la hora de hacer pedagogía, solemos ubicarnos en una comunidad de ideas que compartimos, dominamos y practicamos conjuntamente. Según sea el paradigma aplicado en su práctica pedagógica, se mantendrá o transformará el estatus quo educativo. Con paradigmas tradicionales o de corte positivista, lo máximo alcanzado son reformas ${ }^{4}$ reproductoras del estado actual de cosas, situación diferente puede pasar (y pasa) con paradigmas crítico-complejos propios de una pedagogía crítica comprometida con la trasformación social y cultural.

La pedagogía debe abogar, con urgencia, por la transformación de la realidad, dadas las consecuencias de la modernidad capitalista, la cual, mediante la abstracción de la vida, ha generado la muerte como resultado de una "racionalidad" hartamente instrumentalista (positivismo), lo que ha provocado la destrucción del ambiente y de las relaciones sociales (tejido social), la creación de mitos sacrificiales en nombre del mercado y de los propietarios, y ha caído en un culto al cálculo, ofrendando la vida de pocos para salvar la de muchos... Como hemos señalado, esa tarea urgente de transformación ha sido escasa y postergada por los paradigmas tradicionales legitimadores de la pedagogía establecida; de allí la necesidad de recurrir a otros paradigmas alternativos y críticos que exigen la revisión exhaustiva de las diferentes posibilidades expresadas por la realidad, la cual no está agotada en explicaciones cientificistas, iluministas, objetivistas o racionalistas.

Por el contrario, esas explicaciones instrumentalizadas y de alto contenido ideológico están comprometidas con la conservación del estatus quo que las posibilita, las financia o las promueve, y ha vuelto más cómoda la "vida" de las y los docentes que se ven beneficiados por el estado presente de las cosas, pues no se sienten amenazados por ninguna relación de poder superior. Es decir, se

${ }^{2}$ En la Universidad Nacional de Costa Rica (UNA), se entiende por curso semipresencial aquel que "combina la presencialidad y la virtualidad, en el desarrollo de los procesos de enseñanza y aprendizaje" (UNA, 2008, p. 11). Otros términos usados para este tipo de cursos es blended learning, educación flexible, enseñanza bimodal y formación mixta.

${ }^{3}$ Entendiendo por paradigmas lo que Thomas Kuhn denominó comunidad de científicos que trabajan juntos y, establemente, conforme a una convención de principios y creencias que rigen y determinan la rigurosidad de su actuar como expertos en el campo, o una especie de modelo que estipula las condiciones básicas y necesarias para ser un científico aceptado por esa comunidad.

\footnotetext{
${ }^{4}$ De allí nuestro epígrafe, pues reformar ha sido, históricamente, una práctica de remiendos, de disolución de conflictos o de apaciguamiento de rebeliones por más sinceras, necesarias, urgentes y justas que éstas sean, dejando al pueblo sin participación real y volviéndolo cómplice de las injusticias que contra él se practican.
} 
tiende a reproducir lo establecido por comodidad ideológica, económica y emocional, se ha creado un estado de (falsa) seguridad que me hace sentir bien con lo que hago, me identifica o, al menos, me contiene (reprime) del deseo (pulsión) de realizar cambios (me enajena, como diría Marx). Por ello, no es extraño que los mismos docentes sean quienes suelan oponerse a la trasformación de las estructuras enajenantes y deshumanizantes, tal y como sucede con otros sectores medios de la sociedad. En ellos, ha calado, profundamente, el individualismo moderno.

En ese contexto, hay un miedo a la transformación de las múltiples relaciones estructurales establecedoras del tipo de sociedad en la que vivimos, también hay un temor a perder posesiones, ya sean propiedades, riquezas, estatus, poder, fama... bienes alcanzados en esa sociedad desigual y exaltadora de las competencias personales y sociales. Ese pensamiento individualista, meritocrático y ultramoderno se suele legitimar por medio de la ciencia positivista, con su reduccionismo clasificatorio o taxonómico de los hechos para construir teorías estadísticas explicativas de la realidad, ajenas al investigador (científico) y regidas por códigos de objetividad, los cuales han sido puestos en duda hasta por cientificistas como Popper. Esa pretendida "neutralidad" manifiesta su intención política, ética y estética por reproducir lo establecido, aún y cuando ello implique legitimar la injusticia y la desigualdad social, mediante la conversión del científico y sus mecenas en aliados del sistema moderno capitalista generador de asimetrías, inequidades y desequilibrios...

Así las cosas, es axiomático que el desde dónde (epistemológico) de la pedagogía actual (al menos, la promovida en el CIDE) se aboque al estudio de la práctica educativa desde los sujetos mismos, y se apoye en paradigmas críticos, complejos y alternativos o, dicho de otra forma, en aquellos que promuevan y generen procesos de emancipación, desmitificación y transformación de la realidad, buscando una sociedad más justa en la que quepamos todos y todas (como suele afirmar el movimiento zapatista en México); pero en la que no quepa todo, pues en ella no habría lugar para la injusticia, la exclusión, la destrucción de la naturaleza o el socavamiento de la vida misma.

Por tanto, el desde dónde de la pedagogía también es político y ético, está comprometido con la vida ${ }^{5}$, cuestionará todo sufijo que se le adhiera a la pedagogía (pedagogía social, pedagogía de la diferencia, pedagogía de la diversidad, pedagogía intercultural...), con el fin de determinar si es o no un eufemismo utilizado para acallar conciencias críticas, limpiar el nombre de los evocadores o seguir haciendo más de lo mismo desde otros referentes simplemente nominales. Es decir, desde el caso en cuestión, revisaremos qué se entiende y significa "pedagogía intercultural", y desmitificaremos los esnobismos panfletarios utilizados para tranquilizar nuestras conciencias o legitimar nuestras acciones pedagógicas conformistas, poco críticas y poco comprometidas con la transformación de la realidad y del sujeto humano.

Para nadie es un secreto que la interculturalidad, la diversidad y la diferencia son palabras muy manoseadas y trastocadas por el poder. Concretamente, la interculturalidad suele ser usada como eslogan de mercado con el fin de atraer turismo mediante las vestimentas, comidas, costumbres y tradiciones de distintas comunidades exóticas, las que representan museos vivientes para extranjeros del primer mundo (en su mayoría, estadounidenses y europeos), a quienes, sobre todo, están dirigidos los programas de turismo sostenible. En este caso, la "interculturalidad" es un eufemismo comercial (marketing) o estereotipo promotor de turismo masivo en el que la igualdad, la

\footnotetext{
5. Se parte del binomio integral vida-muerte, pero pensándolo desde la transformación, desde la espiritualidad del sujeto humano, desde un humanismo no abstraccionista ni instrumental que por el contrario se piensa desde el dualismo muerte y vida. Esa integralidad en función de la vida como límite hace defensa del humanismo llevado a cabo desde el sujeto y no desde el individuo. El humanismo desde el sujeto remite al caos, las carencias y la complejidad en general, desmitificando la perfección, el orden establecido y la simplicidad. Ese humanismo plantea, como señala Himmkelamert, un principio de espiritualidad que manifiesta que "yo soy si tú eres".
} 
libertad, la integración, el intercambio y el beneficio cultural, social y económico, son una situación claramente falsa, pues los favorecidos, rara vez, son las comunidades o los grupos culturales. Es decir, en algunos casos, se contribuye, de manera local, con algunos sujetos individuales que hacen negocio de los conocimientos colectivos y ancestrales; pero, la mayoría de las veces, los beneficios son captados por las corporaciones transnacionales y nacionales del turismo empresarial.

Para hablar de pedagogía intercultural, más allá de una visión estereotipada de la cultura, me remito a un desde dónde crítico, reflexivo y comprometido con los sujetos en amplia interrelación entre sí, ya que el nosotros suele ser un déspota moderno "que, a la vez que crea el nosotros crea la alteridad..." (Skliar, 2007, p. 94). Ese compromiso está encaminado, en definitiva, hacia la consecución de la "vida buena"6 o hacia la vida en plena armonía y equilibrio con la naturaleza. Por tanto, la pedagogía será intercultural si reflexiona sobre su quehacer, esto es, si repiensa la enseñanza y el aprendizaje desde la diferencia, desde la autocrítica, la política, la ética y la estética, en pos de la transformación personal y social de la humanidad, o sea, un desde dónde humanista ${ }^{7}$ generador de posibilidades, alternativas y esperanzas.

Lo anterior también nos lleva a revisar otras formas eufemistas de la interculturalidad, por ejemplo, cuando ésta es abordada desde la identidad como cliché lleva a posiciones asimilacionistas o integracionistas que niegan o evitan el diálogo, la comunicación y la convivencia entre culturas; en nombre de la interculturalidad se niega el derecho a la identidad. Esta inversión ideológica persigue afectar el derecho a la autodeterminación, a la autogestión, a la autoeducación y hasta al autogobierno. Justamente, lo anterior afirma a la identidad como punto de partida de la interculturalidad, pero no la identidad vista como un esencialismo irreversible e inamovible, sino como un proceso de auto constitución individual y social alejado de posiciones puristas (etnocéntricas), que funcionan como dispositivos ideológicos legitimadores de un actuar sin consecuencia ni responsabilidad ética.

Tampoco se debería hablar de identidad o identidades en interculturalidad desde lo metafísico, sino desde contextos propios de cada pueblo o persona, desde su territorio, su tierra, su geografía y esto remite, también, al derecho de autonomía y autogobierno de sus tierras, como ya se ha señalado. Por tanto, la interculturalidad permite problematizar sobre la relación entre identidad y territorio, dicotomía occidental creada para romper con la identificación holística ancestral que hacían (y hacen) las comunidades originarias de Abya Yala ${ }^{8}$; desde ese etnocentrismo se justifica la identidad sin derechos, sin tierras y sin autodeterminación, se identifica identidad con propiedad privada y sus valores de herencia liberal.

No obstante lo manifestado, no basta con esa lectura crítica de la identidad, también hay que deconstruir otros patrones ideológicos, tales como las relaciones de poder entre culturas, las desigualdades producidas por sistemas socioeconómicos y políticos injustos, la pérdida permanente de espacios, lenguas y derechos, el constante desplazamiento y migración de los sujetos en búsqueda de mejores condiciones de vida, entre otros. Pero, en todos esos casos, la lucha por revertir esas desigualdades sociales implica una posición pedagógica comprometida, la cual puede desestabilizar nuestro confort y nuestra seguridad ideológica, lógica y epistemológica; es por ello que, cuando la

${ }^{6}$ Tal como lo creen los Aimaras de Bolivia, para quienes la vida no debe ser mejor sino buena, pues lo mejor remite a la comparación y a la competencia, implica estar mejor que otros(as) y por ello, también remite a la exclusión, para que unos estén mejor otros estarán peor. Por el contrario, para ellos la "vida buena" remite a la convivencia, a la colectividad, a la satisfacción de necesidades indispensables para la vida armoniosa y justa, como asegurar la alimentación, la educación, la salud, la tierra, el agua... para todos(as).

${ }^{7}$ Un humanismo comprometido con el sujeto, esto es, con su dimensión tanto social como individual sin caer en abstraccionismos metafísicos que diluyan, difuminen ni ideologicen los intereses, expectativas y necesidades de los sujetos concretos.

${ }^{8}$ Nombre que le daban los Kuna Yala, y otros grupos originarios, a lo que hoy conocemos con el nombre de continente americano. 
pedagogía no nos lleva más allá de lo intuitivo y lo establecido, o no nos choca y revienta contra muros aparentemente infranqueables, no nos percatamos del sutil sometimiento en el que vivimos.

Esa necesidad de desmitificar la interculturalidad como eufemismo lleva a revisar otros posibles esnobismos pedagógicos, tales como el de la diversidad y la diferencia, los cuales se han usado, en muchos casos, para apuntar al diferente, en aras de su normalización y lucrar con la diferencia ${ }^{9}$ y justificar un lenguaje correctamente político en el campo educativo. Sin esa tarea crítica se favorece la reproducción de las condiciones de vida actual, y se pone en entredicho la vida humana, en particular, y la del planeta, en general.

Otro aspecto por revisar, mediante la pedagogía intercultural crítica, ha de ser la categoría de modelaje de las culturas, esto es, evitar que sólo haya una cultura de referencia (la más poderosa) y que, desde ella, se busque "formar" a las demás (asimilacionismo). En suma, al hablar de pedagogía intercultural se debe estudiar, investigar, reflexionar y problematizar la realidad cultural circundante, o detenerse a pensar antes de actuar sobre la realidad, con el fin de evitar que en nombre de la interculturalidad se favorezcan la discriminación, la desigualdad o la injusticia.

Pedagógicamente, lo anterior apunta a la problematización de los "procesos" de enseñanza y de aprendizaje, pues sin saber ni querer, muchas y muchos docentes (re)producen la discriminación, la exclusión y la segregación, incluso en nombre de la interculturalidad, la diferencia o la diversidad, como ya se ha indicado. Ese análisis y reflexión sobre el quehacer pedagógico, necesariamente, nos debería llevar a la determinación de un actuar consecuente, que favorezca el ágape (la comunión) por medio del justo intercambio de experiencias y saberes desde el aprendizaje.

De ese modo, se apunta hacia la tarea de desideologizar la diversidad, problematizarla desde lo plural, aprender desde lo distinto, lo propio de cada persona, comunidad y cultura. Ese compromiso ético, estético y político con la educación podría implicar, como ya se dijo, una realidad adversa en relaciones de poder, desde las cuales podríamos sufrir descalificaciones y etiquetamientos, lo que afectaría nuestro estar confortable en el mundo; es por ello que, para transformar la cultura y la sociedad, debemos estar (in)formados y ser conscientes de las consecuencias de nuestros actos, de modo que nuestro actuar no sea mecánico ni ingenuo.

Así las cosas, la interculturalidad es inclusiva cuando remite al concepto de diversidad, cuando la diferencia es su medio de acción y no su fin, y cuando su fin es la transformación de la sociedad y los sujetos. En ese sentido, cuando la pedagogía se denomina intercultural, sin ir más allá de un esnobismo o etiqueta publicitaria, favorece la discriminación entendida como exclusión y, con ella, hace referencia a la negación de la libertad, no obstante ¿qué entendemos por libertad? Hacemos esa pregunta puesto que, actualmente, al menos en la política real ${ }^{10}$, la libertad ha recibido una "inversión ideológica", ha dejado de remitir a la emancipación y ha pasado a ser sometimiento o dominación, es decir, en nombre de la libertad se somete y se excluye mediante leyes que coartan la libertad misma ${ }^{11}$.

Pero, ¿cuál debería ser ese desde dónde epistemológico y político de la pedagogía costarricense?, en nuestro caso, creemos que la pedagogía crítica latinoamericana suele ser un buen referente a la

${ }_{9}^{9}$ El mercado descubrió la rentabilidad de la diferencia, promueve la venta de mercancías relacionadas con necesidades focales o especializadas y, al mismo tiempo, favorece la venta de artículos exóticos provenientes de culturas inusitadas. Claro está, que la mayor parte de las utilidades quedan en intermediarios o agentes que lucran con el sello personal de esas culturas.

${ }^{10}$ Entiéndase la que se da ontológicamente hablando.

${ }^{11}$ Tal es el caso de las leyes antiterroristas y de las leyes de seguridad pública, presentes a lo largo y ancho del mundo. O en el caso de la interculturalidad destacan las leyes de reservación que remiten al encierro y a la exclusión, se encierra a grupos humanos en extensiones montañosas al estilo de un zoológico en campo abierto. 
hora de transformar la realidad y gestionar enfoques comprometidos con la vida misma, vida de calidad o buena vida; por ello, ese quehacer pedagógico debe problematizar la realidad de las y los educandos, con el fin de evidenciar inversiones ideológicas legitimadoras de la desigualdad en nombre de la igualdad o que, en nombre de la diversidad, justifican la homogenización cultural y la dictadura del pensamiento único.

Las tesis hasta aquí sostenidas nos dicen que la pedagogía costarricense debe sospechar de las palabras mismas, de sus limitaciones, de sus construcciones estereotipadas y de sus inversiones ideológicas, sobre todo, cuando son impuestas desde las dictaduras lexicográficas de especialistas desarraigados de los sentidos y contenidos de los mismos sujetos o de sus realidades; el imperio del idioma contenido en el diccionario suele usarse para legitimar palabras descontextualizadas, ideologizantes y sin equidad de género. Por ejemplo, la palabra libertad es definida por el Diccionario de la Real Academia (DRAE), (2001) como "la condición de quien no es esclavo". El mismo DRAE señala que la libertad es "la facultad natural que tiene el hombre de actuar de una manera u otra"; de tal forma que, según sea el ámbito en donde se ejerza la decisión, puede hablarse de diversas clases de libertad. Tal definición queda huérfana al no establecer una relación entre libertad y auto constitución del sujeto, en el marco de las condiciones físico-volitivas y el poder real que posee el ser humano de decidir y auto constituirse como sujeto autónomo, y en la que se involucran los conceptos de independencia, autonomía y autogobierno. Por tanto, la definición de DRAE es reduccionista y determinista ${ }^{12}$.

Así pues, siguiendo este sano sentido de la sospecha o revisión crítica de las palabras, si entendemos por discriminación aquel proceso de negación de libertad que lleva a la exclusión y a la libertad como un proceso de lucha y de conquista, complejo y limitado, entonces, estamos diciendo que la "imposibilidad" o la negación del derecho ${ }^{13}$ a la libertad, o, concretamente, a la autodeterminación (auto constitución individual o social) son formas de discriminación. De este modo, cuando se le niega ese derecho o no se facilitan las condiciones necesarias de igualdad y de equidad a las personas más desiguales en relaciones de poder en el aula ${ }^{14}$, o con menos poder, como a las mujeres, los niños, los jóvenes, los ancianos, los indígenas, los campesinos, los negros, los migrantes, los pobres... les estamos discriminado, segregando y excluyendo.

En Costa Rica, desde sus orígenes como Estado Nacional se ha discriminado a las poblaciones con menos poder político, económico y social ${ }^{15}$, se han construido mitos y discursos desde los cuales sólo una clase social parece habitar el país. Esa discriminación política, económica y cultural ha perdurado hasta nuestros días mediante mitos como el de la Suiza Centroamericana ${ }^{16}$. En esta línea, según el censo de 1927, los(as) negros(as), en Costa Rica, eran considerados(as) extranjeros(as) y, en 1934, se les negaba el desplazamiento a otras regiones del país tal como lo impuso don Ricardo Jiménez Oreamuno, presidente de la época; es hasta 1949 cuando se les considera

\footnotetext{
${ }^{12}$ En nombre de la libertad, se excluye la posibilidad de la emancipación, pues para dicha definición la libertad depende de "condiciones" internas y externas al sujeto. Ese dualismo modernista reduce la libertad a un problema de la voluntad y a problemas sociológicos y políticos o de "poder". Es decir, no incorpora los procesos de conquista, de lucha y de determinación para alcanzar grados posibles de libertad y de emancipación.

${ }^{13}$ Siguiendo la tradición de Occidente.

${ }^{14} \mathrm{O}$ en cualquier otro lugar de aprendizaje o de la vida, en general.

${ }^{15}$ Concretamente, a las mujeres, al campesinado, a las(os) migrantes, a los(as) indígenas, a las(os) obreros, a los(as) negros, entre otros sectores cercanos de la exclusión.

${ }^{16}$ Esa Costa Rica blanca, europea, mejor de Centroamérica... fue la imaginada e impuesta por los liberales del Olimpo costarricense desde finales del siglo XIX.
} 
ciudadanos costarricenses (Villegas, 1986). Situación nada accidental ni aislada, pues los indígenas de Talamanca esperaron hasta 1995 para que se les diera cédulas de identidad, se les "reconoció" su ciudadanía, aunque vaciada de derechos interculturales, no se pasa del nivel ideológico o del lenguaje "políticamente correcto".

En nuestro país, el campesinado también ha sufrido un sinnúmero de atropellos asimilacionistas; a finales del siglo XIX, se les incluyó en un proceso de blanqueamiento nacional y se utilizó la educación como medio ideologizante para convencerles de la necesidad de la segregación del resto del país y de las naciones vecinas, acoso y exclusión que no ha terminado, incluso se radicalizó con las políticas neoliberales de los años 90, lo que promovió la reconversión económica, la desmovilización campesina y el abandono de sus saberes. Las mujeres tampoco han sido la excepción en materia de discriminación, es hasta finales del siglo XIX cuando se les da el derecho a la educación y, en 1952, el derecho al voto, ambos eran derechos reservados a varones "blancos", dueños de las tierras y de los capitales, a quienes podían pagar impuestos y a quienes sabían leer y escribir. Así, también, se excluía al resto de la población del acceso de cargos públicos, esa realidad de desigualdad y discriminación sigue presente, sobre todo, contra las y los migrantes, campesinos e indígenas.

Cabe señalar que las mujeres y otros sectores marginados ${ }^{17}$ de la sociedad han logrado adquirir derechos reservados a los varones blancos y oligarcas, como producto de resistencias, presiones, luchas, revueltas, levantamientos, guerras..., lo que indica su condición de conquista social, pues no cayeron del cielo, sino que son producto de luchas históricas emancipatorias o conquistas de libertad. Tales logros aún son insuficientes para un país como el nuestro que ha crecido en la desigualdad social, política, económica y cultural, según lo refiere el II Informe del Estado de la Educación (Programa Estado de la Nación/Consejo Nacional de Rectores, 2008).

Esos procesos discriminatorios refieren a una renuncia sistemática de la diversidad en el campo de la educación, en particular, y de las políticas públicas, en general, situación (re)producida por los grupos más poderosos (oligarcas, empresarios, gobernantes) quienes no han dudado en utilizar a la educación, entre otros, como medio eficaz de justificación demagógica, con el fin de perpetuar sus privilegios y derechos burgueses, y realizar una inversión ideológica, pues se permite ampliar la cobertura educativa (educar a la nación) con la intención de legitimarse a través de ella. Esto significa que se extiende el "derecho" a la educación, pero se niega el derecho a la transformación o se entiende educación como maquinaria ideológica de la reproducción desigual de la sociedad, y no como la transformadora del sujeto humano a partir de la diversidad.

Ese segregacionismo se sigue oficializando en las escuelas, en nombre de la igualdad se sigue homogenizando la diversidad en el aprendizaje y en nombre de la diferencia se acentúa el diferencialismo, ambos se apuntan como una patología por corregir, por normalizar y por disciplinar (muchas de las adecuaciones curriculares, impuestas por el $\mathrm{MEP}^{18}$, no salen de este espectro). Esta realidad nos invita a buscarle posibles soluciones a la discriminación, lo que podemos potenciar desde una pedagogía intercultural crítica, creativa, promotora y creadora de alternativas, alejada de los recetarios o respuestas elaboradas desde afuera y desde arriba, remitiendo a la construcción participativa desde los diferentes grupos y sujetos involucrados e interesados, desde abajo y desde adentro, y gestionando diálogos con los distintos sectores de la sociedad.

Por tanto, la pedagogía intercultural debería fundamentarse en el pensar crítico y alternativo, si pretende transformar la realidad y, desde allí, dar sustento teórico a la pedagogía de la diferencia.

\footnotetext{
${ }^{17}$ La pedagogía costarricense en la práctica sigue operando como una pedagogía dominante revestida de ropajes "políticamente correctos" y aparentemente críticos produciendo, escondiendo y legitimando la discriminación. Lo anterior no impide la posibilidad de desarrollar una pedagogía crítica, y comprometida con esos actores sociales, que rompa con esas tendencias excluyentes de mujeres, niños(as), adultos mayores, indígenas, grupos rechazados por sus preferencias sexuales, campesinos...

${ }^{18}$ Ministerio de Educación Pública de Costa Rica.
} 
La pedagogía intercultural ha de ser vista como una pedagogía de la vida y para la vida, sin caer en "inversiones ideológicas" o sin producir la muerte en nombre de la vida, la crítica le lleva a estar atenta, en vela, haciendo crítica de la crítica (como diría el mismo Adorno). Ese es el desde dónde la pedagogía puede ubicarse para abordar las desigualdades, la discriminación y la injusticia social que reproduce la pedagogía tradicional, moderna y positivista, ligada al pensamiento único el cual transmite discursos de obediencia, de conformismo, de normalización y de legalización de la inequidad, perpetuando, así, un sistema sin alternativas.

\section{Referencias bibliográficas}

Brecht, B. (1934). Las cinco dificultades para decir la verdad. Recuperado el 5 de enero, 2009, de http://www.lainsignia.org/2004/enero/cul 062.htm

Programa Estado de la Nación en Desarrollo Humano Sostenible. (2008). CONARE (Coord.). II Informe sobre el Estado de la Educación Costarricense. San José, Costa Rica: Proyecto Estado de la Nación.

Real Academia Española. (2001). Diccionario de la lengua española (22a ed.). Madrid, España: Espasa Calpe.

Skliar, C. (2007). La educación (que es) del otro. Argumentos y desierto de argumentos pedagógicos. Buenos Aires, Argentina: Editorial Novedades Educativas.

Universidad Nacional de Costa Rica [UNA]. (2008, Junio). Procedimientos sobre los procesos de enseñanza y de aprendizaje de la Universidad Nacional. Recuperado el 5 de enero, 2009, de http://www.una.ac.cr//index.php?option=com_remository\&Itemid=0\&func=fileinfo\&id=5

Villegas, R. (1986). El Tribunal Supremo de Elecciones y el Registro Civil de Costa Rica: análisis jurídico, estructural y técnico. San José, Costa Rica: Tribunal Supremo de Elecciones. 